[Agr. Biol. Chem., Vol. 29, No. 3, p. 216 221, 1965]

\title{
Isolation of Helminthosporol as a Natural Plant Growth-regulator and its Chemical Structure*
}

\author{
By Saburo Tamura, Akira SakuraI, Kihei KaInuma and Makoto TakaI \\ Department of Agricultural Chemistry, The University of Tokyo, \\ Tokyo \\ Received September 14, 1964
}

\begin{abstract}
Helminthosporol was isolated as a natural plant growth-regulator produced by $\mathrm{Hel}$ minthosporitum sativum and its structure was assigned as I. Oxidation of I with chromium trioxide-pyridine complex gave helminthosporal (II). The glycol (III), obtained by the reduction of I or II, yielded I by the oxidation with activated manganese dioxide. I spontaneously changed into helminthosporic acid (IV), when the former in organic solvent was let to stand in the air.
\end{abstract}

In the course of the screening research to find out new plant growth-regulators among metabolites of phytopathogenic fungi, it was observed that cultured broth of Helminthosporium sativum markedly promoted shoot growth of rice seedlings. Then isolation of the active principle contained in the broth was undertaken.

The fungus was grown on the medium containing corn steep liquor-sucrose or potatosucrose under aeration. The cultured broth was filtered and the filtrate was treated with charcoal. The charcoal and the mycellia separated were extracted respectively with acetone. The neutral fraction from these acetone extracts was purified by silicic acid column chromatography and crystallized from $n$-hexane. Thus the active principle was obtained as colorless needles melting at $98^{\circ} \mathrm{C}$. Its chemical structure was elucidated as I in the following way, and the name, helminthosporol, was proposed to this compound due to its structural relation to helminthosporal (II) isolated by the Canadian workers. ${ }^{11}$

* A preliminary report has been published in this Journal, 27, 738 (1963).

1) P. de Mayo, E. Y. Spencer and R. W. White, Can. I. Chem., 39, 1608 (1961); J. Am. Chem. Soc., 84, 494 (1962); Can. J. Chem., 41, 2996 (1963).

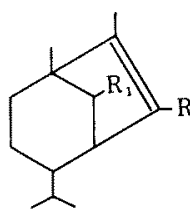

\begin{tabular}{rll} 
& \multicolumn{1}{c}{$\mathrm{R}_{1}$} & \multicolumn{1}{c}{$\mathrm{R}_{2}$} \\
I & $\mathrm{CH}_{2} \mathrm{OH}$ & $\mathrm{CHO}$ \\
II & $\mathrm{CHO}$ & $\mathrm{CHO}$ \\
III & $\mathrm{CH}_{2} \mathrm{OH}$ & $\mathrm{CH}_{2} \mathrm{OH}$ \\
IV & $\mathrm{CH}_{2} \mathrm{OH}$ & $\mathrm{CO}_{2} \mathrm{H}$
\end{tabular}

The molecular formula $\mathrm{C}_{15} \mathrm{H}_{24} \mathrm{O}_{2}$ was assigned to $\mathrm{I}$ through elemental analysis and molecular weight determination. Its infrared spectrum, shown in Fig. 1, suggested that two oxygen atoms could be attributable to an alcohol and a carbonyl groups. These were confirmed directly by the preparation of corresponding acetate and 2,4-dinitrophenylhydrazone. The fact that the carbonyl group corresponds to aldehyde was proved by the infrared spectrum of I in carbon tetrachloride solution showing a band at $2740 \mathrm{~cm}^{-1}$ and also by the NMR spectrum indicating a sharp singlet at $\tau-0.2$ equivalent to one proton. The ultraviolet spectrum of I showed a band with high intensity at $267 \mathrm{~m} \mu$ indicating the presence of some conjugation, whereas in that of the glycol (III), obtained by the reduction of I with sodium borohydride, no absorption band was observed above $210 \mathrm{~m} \mu$. Thus it 


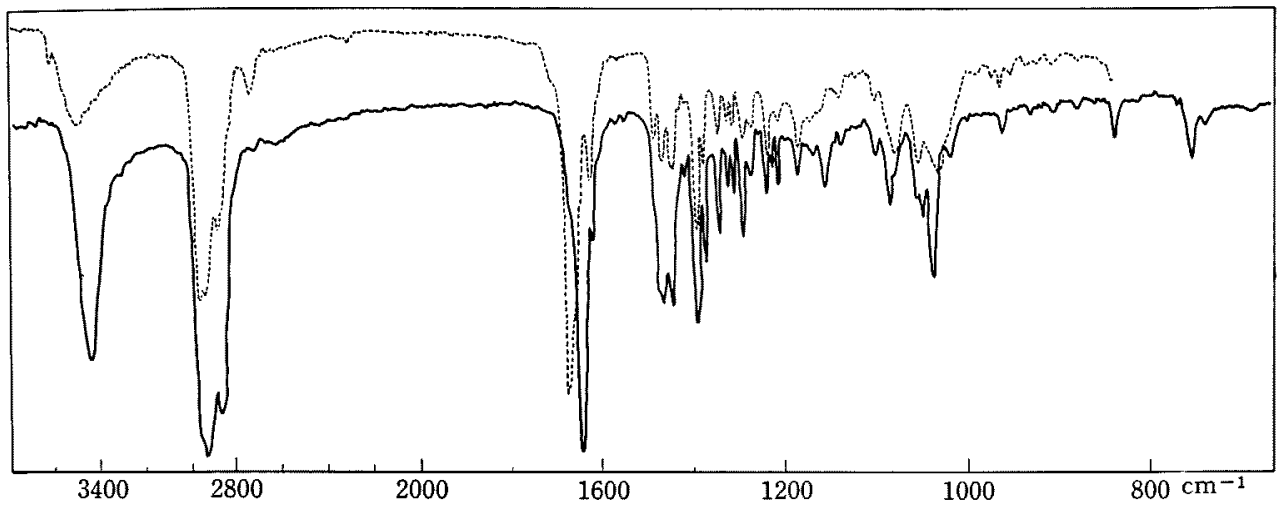

FIG. 1. Infrared Spectrum of Helminthosporol.

- Nujol mull. - - Carbon tetrachloride solution.

has been revealed that an $\alpha, \beta$-unsaturated aldehyde is contained in I. In addition, the double bond must be a tetra-substituted one since no band attributable to olefinic proton was observed in the NMR spectrum.

Thus the possibility arose that helminthosporol might have a structure related to helminthosporal, which was isolated as a toxin produced by Helminthosporium sativum, ${ }^{*}$ its structure being already assigned as II. The structural relationship was demonstrated by identifying bis-3,5-dinitrobenzoate of the aforementioned glycol with that derived from $\mathrm{II}^{1 \prime}$ through the mixed melting point and the comparison of infrared spectra. Thus the structure of helminthosporol has been reasonably proposed as I, and this was further confirmed by the success in direct transformation of I to II. Oxidation of I with chromium trioxide-pyridine complex gave a neutral compound, which was crystallized from $n$-hexane to give colorless crystals melting at $52 \sim 56^{\circ} \mathrm{C}$. This compound was proved to be identical with helminthosporal, kindly supplied by Drs. de Mayo and Spencer, through mixed melting point and the comparison of the infrared spectra as is shown in Fig. 2. Moreover the glycol (III), obtained from both I and II,

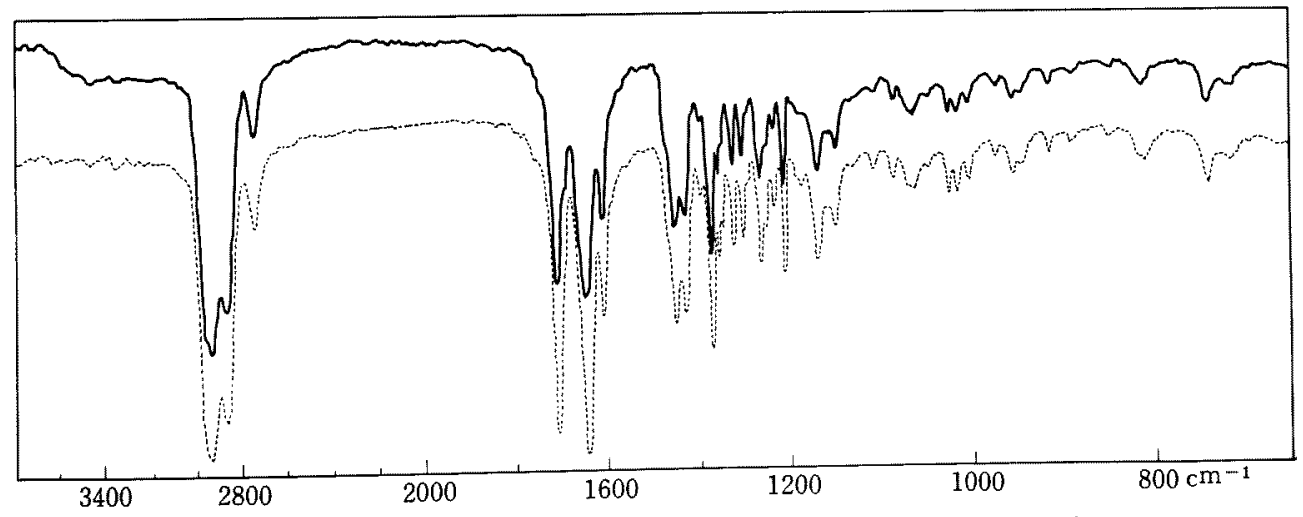

FIG. 2. Comparison of Infrared Spectrum of the Oxidation Product from

Helminthosporol ( $-\cdots \cdot-\cdot)$ with that of Helminthosporal (-). Nujol mull. * De Mayo et al. noted that their strain had been recently
reclassified as Bipolaris sorokiniana. ${ }^{1)}$ 
afforded $I$ when it was oxidized with activated manganese dioxide. These findings confirm the validity of the structure I and, therefore, the route for interconversion between helminthosporol and helminthosporal was thus established.

When I was subjected to air oxidation in organic solvents such as benzene, chloroform, ethyl acetate or ether, it changed into a hydroxy acid, $\mathrm{C}_{15} \mathrm{H}_{24} \mathrm{O}_{3}$, which was designated as helminthosporic acid. The infrared spectrum of this acid showed bands at 3370 (alcohol), 1675 (carboxyl), $1620 \mathrm{~cm}^{-1}$ and the ultraviolet absorption maximum was observed at $245 \mathrm{~m} \mu$ ( $\varepsilon 9000)$. The NMR spectrum of its acetyl derivative showed a singlet at $\tau-2.3$, indicating that the aldehyde proton in $\mathrm{I}$ was replaced by the carboxyl one. This means the occerrence of simple oxidation of $\alpha, \beta-$ unsaturated aldehyde into $\alpha, \beta$-unsaturated carboxylic acid, and the structure IV was assigned to this acid. The correctness of this structure was further confirmed by the lithium aluminum hydride reduction of the methyl ester of IV to give the same glycol (III).

A part of the investigation on plant growthregulating activities of $\mathrm{I}$ and its related compounds has been reported ${ }^{2,3)}$ and details will be described in the following paper.

\section{EXPERIMEMTAL}

Infrared measurements were made with Koken DS 301 and JASCO IR-S KCl spectrophotometers, and ultra. violet spectra were measured with Cary 14-PM spectrophotometer. NMR spectra were measured with Varian A-60 spectrometer in carbon tetrachloride solution at a concentration of $100 \mathrm{mg} / \mathrm{ml}$. Melting points were

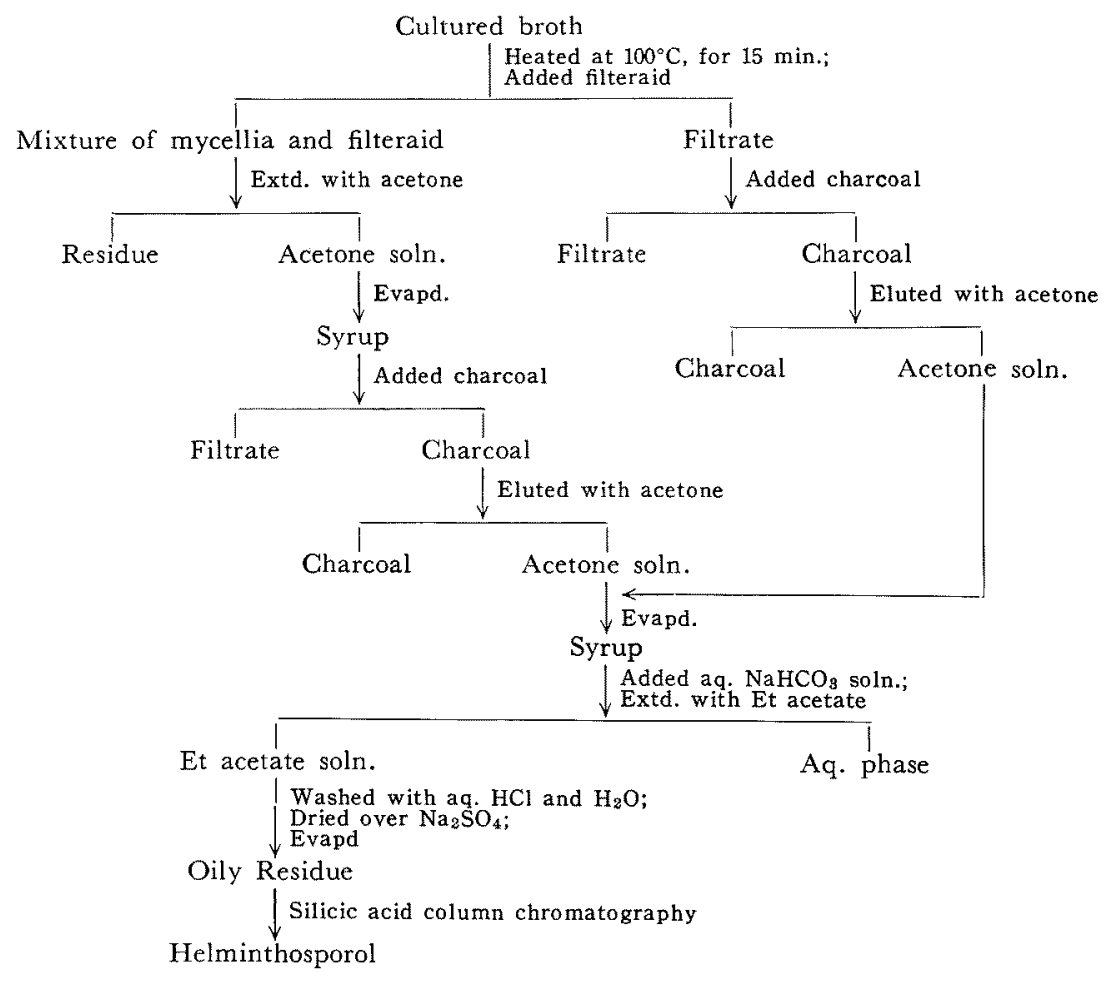

FIG. 3. Isolation Procedure of Helminthosporol.

\footnotetext{
2) J. Kato, Y. Shiotani, S. Tamura and A. Sakurai, Naturwiss., 51, 341 (1964).

3) S. Tamura, A. Sakurai, This Journal, 28, 337 (1964).
} 
uncorrected.

\section{Isolation of Helminthosporol.}

Helminthosporium sativum on agar slant of potatosucrose medium was transferred into three $500 \mathrm{ml}$. shaking flasks containing $100 \mathrm{ml}$. each of potato-sucrose medium and incubated for $72 \mathrm{hrs}$. The contents in the flasks were transferred into a 1001 . jar fermenter charged with $40 \mathrm{~L}$. of the medium containing $2.0 \%$ sucrose and $1.5 \%$ corn steep liquor, and incubated at $30^{\circ} \mathrm{C}$. for $28 \mathrm{hrs}$. under aeration. This seed culture was transferred into a $600 \mathrm{l}$. fermentation tank containing $300 \mathrm{l}$. of the same medium, and cultivated at $30^{\circ} \mathrm{C}$. for $48 \mathrm{hrs}$ under aeration.

A schematic outline of isolation procedure of helminthosporol from this cultured broth is shown in Fig. 3. The broth obtained by the above process was heated at $100^{\circ} \mathrm{C}$. for $15 \mathrm{~min}$. and $12 \mathrm{~kg}$. of celite added. After stirring the mixture was filtered. The filtrate was stirred for $2 \mathrm{hrs}$. with $3.5 \mathrm{~kg}$. of charcoal, on which the active principle was adsorbed. The charcoal was eluted with 501 . of acetone. On the other hand, the mixture of celite and mycellia separated was extracted with 1001 . of acetone, followed by filtration and evaporation of the acetone in vacuo to give a residual syrup (30 l.). To this residue $2 \mathrm{~kg}$. of charcoal was added and stirred for $2 \mathrm{hrs}$. and the charcoal was eluted with 351 . of acetone.

The acetone eluates from the two different origins were combined and concentrated in vacuo. The resulting aqueous solution (11.) was adjusted to $\mathrm{pH} 8$ with sodium bicarbonate, and extracted three times with 11. each of ethyl acetate. The solvent layers were combined, washed with $5 \%$ hydrochloric acid and water successively and dried over anhydrous sodium sulfate. After evaporation of the solvent in vacuo, an oily residue $(80 \mathrm{~g}$.) was obtained. A half amount of this oil was dissolved in benzene and applied to a silicic acid column (Mallinckrodt, $300 \mathrm{~g}$.) which was eluted successively with 21 . each of benzene and benzene- $2 \%$ ethyl acetate, and finally with 61 . of benzene-7\% ethyl acetate. When the solvent of the last fraction was evaporated in vacuo, crystals $z$ of I were obtained in a yield of $6.7 \mathrm{~g}$.

\section{Properties of Helminthosporol.}

The crystals thus obtained were recrystallized from $n$-hexane to give colorless needles melting at $98^{\circ} \mathrm{C}$. $[\alpha]_{\mathrm{D}}^{23}-28.7^{\circ}$ (c 1.93, in chloroform), $\lambda_{\max } 267 \mathrm{~m} \mu$ ( 9700 in $95 \%$ ethanol), $\nu_{\max }^{\text {Nujol }} 3440,1645,1610$, $1025 \mathrm{~cm} .{ }^{-1}$; $\nu_{\max }^{\mathrm{COl}_{4}} 3500,2740,1665,1620 \mathrm{~cm} .^{-1}$ Anal. Found: C, 76.22; H, 10.14; M.W. 227 (Rast). Calcd. for $\mathrm{C}_{15} \mathrm{H}_{24} \mathrm{O}_{2} ; \mathrm{C}, 76.22 ; \mathrm{H}, 10.24 \% ; \mathrm{M} . \mathrm{W} .236$. It is soluble in most of organic solvents such as benzene, chloroform, ethyl acetate, ether, acetone and alcohols, but almost insoluble in water.

2,4-Dinitrophenylhydrazone was obtained by the treatment of I with 2,4-dinitrophenylhydrazine hydrochloride in ethanolic sulfuric acid, followed by recrystallization of the precipitate from ethanol-water. M. p. $158 \sim 160^{\circ}$ C. Anal. Found: C, $60.24 ; \mathrm{H}, 6.76$; $\mathrm{N}$, 13.34. Calcd. for $\mathrm{C}_{21} \mathrm{H}_{28} \mathrm{O}_{5} \mathrm{~N}_{4}: \mathrm{C}, 60.56 ; \mathrm{H}, 6.78$, $\mathrm{N}, 13.45 \%$.

Acetate was prepared as follows. I was treated with pyridine-acetic anhydride at room temperature overnight. The reaction mixture was poured into ice-water and extracted with ether. The ether solution was washed with dilute sulfuric acid, aqueous sodium bicarbonate and water successively and evaporated to give an yellow oil. This oil was purified by silicic acid column chromatography and eluted with benzene-2\% ethyl acetate. After evaporation of the solvent, the acetate was obtained as a colorless oil. $\nu_{\max } 1735,1660,1250 \mathrm{~cm}$. This oily acetate was rather unstable, so that it was converted into a semicarbazone by treatment with semicarbazide hydrochloride and sodium acetate in ethanol-water. The reaction mixture was diluted with water and extracted with ether. After evaporation of the ether solution, the residual solid was recrystallized from ethanolwater to give colorless crystals of the semicarbazone. M. p. $206 \sim 209^{\circ}$ G. Anal. Found: C, $64.28, \mathrm{H}, 8.71$; $\mathrm{N}, 12.31$ Calcd. for $\mathrm{C}_{18} \mathrm{H}_{29} \mathrm{O}_{3} \mathrm{~N}_{3}: \mathrm{C}, 64.45 ; \mathrm{H}, 8.72$; N, $12.53 \%$.

\section{Sodium Borohydride Reduction of Helmintho- sporol.}

To a solution of $200 \mathrm{mg}$. of I in $5 \mathrm{ml}$. of methanol was added in portions $200 \mathrm{mg}$. of sodium borohydride. The reaction mixture was let to stand at room temperature overnight. Then it was poured into water and extracted with ether. The solvent layer was washed with water and dried over anhydrous sodium sulfate. After evaporation of the solvent the glycol was obtained as a colorless oil, which showed no absorption band above $210 \mathrm{~m} \mu$ in its ultraviolet spectrum.

To a solution of $20 \mathrm{mg}$. of this glycol in $1 \mathrm{ml}$. of pyridine was added $150 \mathrm{mg}$. of 3,5-dinitrobenzoyl chloride. The mixture was let to stand at room temperature overnight, and then poured into ice-water. The resulting solution was extracted with ether after acidification, and the solvent layer was washed with aqueous sodium bicarbonate and water succesively 
and evaporated. The residue was recrystallized from methanol to give bis-3,5-dinitrobenzoate melting at $151 \sim 152^{\circ} \mathrm{C}$. No depression was observed in m. p. by the admixture with the dinitrobenzoate from helminthosporal.1) Anal. Found: C, 55.39; H, 5.03.; N. 9.30. Calcd. for $\mathrm{C}_{29} \mathrm{H}_{80} \mathrm{O}_{12} \mathrm{~N}_{4}: \mathrm{C}, 55.59 ; \mathrm{H}, 4.83$; N, $8.94 \%$.

\section{Oxidation of Helminthosporol to Helminthospo- ral.}

A solution of $200 \mathrm{mg}$. of $\mathrm{I}$ in $2 \mathrm{ml}$. of pyridine was added in portions to pyridine-chromium trioxide complex prepared from $200 \mathrm{mg}$. of chromium trioxide and $2 \mathrm{ml}$. of pyridine. The mixture was let to stand at room temperature for $17 \mathrm{hrs}$. and then poured into ice-water, which was subjected to continous ether extraction after acidification with dilute sulfuric acid and dried over anhydrous sodium sulfate. After evaporation of the solvent, there was obtained $130 \mathrm{mg}$. of an oily product, which was chromatographed on $5 \mathrm{~g}$. of silicic acid column and eluted with benzene. Evaporation of the solvent gave a dialdehyde $(40 \mathrm{mg}$.) which was recrystallized from $n$-hexane. M. p. 52 $56^{\circ} \mathrm{C}$., undepressed by the admixture with II supplied by Drs. de Mayo and Spencer. Moreover its infrared spectrum was identical in every respect with that of II.

Oxidation of the Glycol (III) to Helminthosporol.

To a solution of $270 \mathrm{mg}$. of III in $15 \mathrm{ml}$. of chloroform was added $3 \mathrm{~g}$. of activated manganese dioxide. The reaction mixture was stirred at room temperature for 3 hrs. After filtration, the solvent was evaporated to dryness. The residue was dissolved in benzene and chromatographed on $4 \mathrm{~g}$. of silicic acid column, which was eluted with benzene-7\% ethyl acetate. Oxidation product thus obtained was recrystallized from $n$-hexane in the yield of $104 \mathrm{mg}$. M. p. 96 $97^{\circ} \mathrm{C}$. No depression of $\mathrm{m}$. p. was observed by the admixture with the specimen of helminthosporol and infrared spectra were identical in every respect.

\section{Oxidation of Helminthosporol to Helminthosporic} Acid.

I $(100 \mathrm{mg}$.) was dissolved in $10 \mathrm{ml}$. of benzene, chloroform, ethyl acetate or ether and let to stand at room temperature for 6 days. Then the solution was exracted with aqueous sodium bicarbonate and the aqueous layer thus obtained was extracted with ether after acidification with dilute sulfuric acid. Evaporation of the ether gave IV, which was recrystallized from benzene to give colorless crystals melting at $162 \sim 164^{\circ} \mathrm{C}$. (sublime at $152 \sim 154^{\circ} \mathrm{C}$.) $[\alpha]_{D}^{25}-24.0^{\circ}$ (c 1.46 , in $95 \%$ ethanol). $\lambda_{\max } 245 \mathrm{~m} \mu(\varepsilon 9000$ in $95 \%$ ethanol) $\nu_{\max }^{N u j o l} 3380,1675,1620 \mathrm{~cm} .^{-1}$ Anal. Found: C, 71.55; H, 9.42; titration equivalent 257 . Calcd. for $\mathrm{C}_{15} \mathrm{H}_{24} \mathrm{O}_{3}: \mathrm{C}, 71.39 ; \mathrm{H}, 9.59 \%$; titration equivalent 252.

By the reaction condition above mentioned $20 \sim$ $40 \%$ of I was converted into IV. In the methanolor ethanol-water, however, I was rather more stable to air oxidation and the yield of the acid product was $5 \sim 7 \%$. Because of its instability $I$ even in crystalline state is usually contaminated with $1 \sim 7 \%$ of IV if the former has been stored for a long time.

Acetate was prepared as follows. IV was treated with pyridine-acetic anhydride at room temperature overnight. The reaction mixture was poured into ice-water and extracted with ether after acidification with dilute sulfurid acid. The ether solution was thoroughly washed with water and dried over anhydrous sodium sulfate. Evaporation of the solvent gave a crude acetate which was recrystallized from $n$-hexane to give colorless crystals, melting at $97 \sim 98^{\circ} \mathrm{C}$. $\boldsymbol{\nu}_{\max }^{\mathrm{Nujol}}$ 1730, 1660, 1612, $1230 \mathrm{~cm} \cdot .^{-1}$ Anal. Found: C, 69.48; $\mathrm{H}, 8.90$. Calcd. for $\mathrm{C}_{17} \mathrm{H}_{26} \mathrm{O}_{4} ; \mathrm{C}, 69.36 ; \mathrm{H}, 8.90 \%$.

\section{Lithium Aluminum Hydride Reduction of Hel- minthosporic Acid Methyl Ester.}

II gave an oily methyl ester by treatment with etherial diazomethane. $\nu_{\max } 3470,1705,1630 \mathrm{~cm}$. Anal. Found: C, 72.15; $\mathrm{H}, 10.35$. Calcd. for $\mathrm{C}_{16} \mathrm{H}_{26} \mathrm{O}_{3}: \mathrm{C}, 72.14$; $\mathrm{H}, 9.84 \%$.

To a solution of $500 \mathrm{mg}$. of lithium aluminum hydride in $50 \mathrm{ml}$. of ether a solution of $160 \mathrm{mg}$. of this methyl ester in $20 \mathrm{ml}$. of ether was slowly added with stirring, and the mixture was refluxed for 1.5 hrs. After the excess hydride was decomposed with ethyl acetate, dilute hydrochloric acid was added to the mixture. The product was extracted with ether, and the solvent layer was washed with water and dried over anhydrous sodium sulfate. After evaporation of the solvent, glycol was obtained as a colorless oil. (145 mg.). This glycol was converted to bis-3,5-dinitrobenzoate in the same way as described above. m. p. and mixed m. p. were $150 \sim 151^{\circ} \mathrm{C}$. respectively. It was identical in every respect with that of the glycol from helminthosporol.

Acknowledgement. The authors wish to express their thanks to Drs. M. Matsui and $Y$. Mase, Sankyo Co., for the cooperation to prepare the sample of helminthosporol by 
fermentation. They are also grateful to Drs. Microbiology of the University of Tokyo, and P. de Mayo and E. Y. Spencer for their gener- Department of Agricultural Chemistry of the ous gifts of helminthosporal and bis-3,5- University of Tokyo. Thanks are also due dinitrobenzoate of the glycol. They are also to Sankyo Co. for NMR measurements and indebted to the members of the laboratories to Mr. K. Aizawa for his measurements of for microanalysis in Institute of Applied infrared and ultraviolet spectra. 